\title{
Candida endophthalmitis associated with intraocular lens implantation: efficacy of fluconazole therapy
}

\author{
Candida-Endophthalmitis nach intraokulärer Linsenimplantation: \\ Wirksamkeit der Fluconazol-Therapie
}

\author{
Carol A. Kauffman', Suzanne F. Bradley ${ }^{2}$ and A. K. Vine ${ }^{3}$
}

Key words. Candida parapsilosis, endophthalmitis, intraocular lens implant, fluconazole, antimycotic chemotherapy.

Schlüsselwörter. Candida parapsilosis, Endophthalmitis, intraokuläre Linsenimplantation, Fluconazol, antimykotische Chemotherapie.

Summary. Four patients with Candida parapsilosis endophthalmitis following intraocular lens implantation were treated with oral fluconazole. All had failed prior therapy with intravitreal amphotericin B. The only patient who had the lens implant removed was cured after treatment with fluconazole for one year. Three patients who did not have the lens implant removed had resolution of symptoms and return of visual acuity towards normal during the year they were on fluconazole. However, five months after therapy had been stopped, all three had decreasing visual acuity, and in two, culture of vitreous fluid yielded $C$. parapsilosis. Fluconazole may be effective for treatment of endophthalmitis associated with an intraocular lens implant, but only when the implant is removed also.

Zusammenfassung. Vier Patienten mit Candida parapsilosis-Endophthalmitis nach intraokulärer Linsenimplantation wurden oral mit Fluconazol behandelt. Bei allen Patienten hatte die vorherige intravitreale Amphotericin B-Therapie versagt. Einem Patienten wurde die implantierte Linse entfernt; er war nach einjähr-

\footnotetext{
'Department of Veterans Affairs Medical Center, ${ }^{2}$ Division of Infectious Diseases, Department of Internal Medicine, and ${ }^{3}$ Department of Ophthalmology, University of Michigan Medical School, Ann Arbor, Michigan, USA.

Correspondence: Professor Dr Carol A. Kauffman, Veterans Affairs Medical Center, 2215 Fuller Road, Ann Arbor, Michigan 48105, USA.
}

iger Fluconazol-Therapie geheilt. Den drei anderen Patienten wurde die implantierte Linse nicht entfernt. Unter einjähriger Fluconazol-Therapie besserten sich zwar die Symptome, und die Sehschärfe normalisierte sich. Fünf Monate nach Beendigung der Therapie verschlechterte sich jedoch bei allen drei Patienten die Sehfähigkeit wieder, und bei zwei von ihnen konnte aus der Glaskörperflüssigkeit wieder $C$. parapsilosis isoliert werden. Fluconazol kann also bei Endophthalmitis nach Linsenimplantation wirksam sein, jedoch nur wenn das Implantat wieder entfernt wird.

\section{Introduction}

An uncommon and dreaded complication of cataract extraction and intraocular lens implantation is fungal endophthalmitis. Outbreaks and individual case reports of fungal endophthalmitis due to filamentous fungi and yeasts, such as Candida, have been described [1-6]. In most reports of fungal endophthalmitis associated with intraocular lens implantation, the outcome has been poor. One reason for this is possibly the poor penetration of most antifungal drugs into the eye [7-9]. Fluconazole is a bis-triazole antifungal agent which has been shown to penetrate into both the vitreous body and aqueous humour of the eye $[9,10]$. We report on our experience with fluconazole in the treatment of four patients who had Candida parapsilosis endophthalmitis following cataract extraction with implantation of an intraocular lens. 


\section{Patients and methods}

Four patients with culture-proven $C$. parapsilosis endophthalmitis following implantation of a posterior chamber intraocular lens were evaluated and treated between January 1989 and September 1990. Treatment was $400 \mathrm{mg}$ of oral fluconazole daily, except in one patient who had renal insufficiency and received $200 \mathrm{mg}$ daily. Informed consent was obtained prior to beginning fluconazole therapy. Symptoms and ocular findings were followed monthly for the duration of therapy, which was one year in all patients, and follow-up was carried out for two years after therapy was completed.

\section{Results}

The four patients, three of whom were women, were 66 to 74 years of age (Table 1). All had undergone extracapsular cataract extraction and had a posterior chamber intraocular lens implanted. Following the implantation, visual acuity improved in all patients, but one to four months later all experienced a gradual decrease in visual acuity and patients 1,3 and 4 had intraocular pain.

Over the course of their infection, all four patients had mild to moderate flare and cells in the anterior chamber, keratitic precipitates, and vitritis present. Patient 1 developed an hypopyon, and patient 3 developed a rhegmatogenous reti- nal detachment. Light perception was intact in all patients. Three patients could see only gross movement in the affected eye. None had any systemic symptoms, such as fever, weight loss or fatigue.

The diagnosis of Candida endophthalmitis was made by culture of the vitreous aspirate in two patients and by culture of the vitrectomy and posterior capsulotomy tissue in two patients. The diagnosis was not made until six months after lens implantation in three patients and ten months after implantation in the remaining patient. Prior to the diagnosis of Candida infection, all patients had been treated with topical, paraocular or intravitreal cortiosteroids, and patients 1 and 3 had received oral prednisone.

After the diagnosis of Candida endophthalmitis was made, initial antifungal treatment in all four patients was intravitreal amphotericin B; in addition, patient 1 had intravenous amphotericin B for one week and flucytosine for two weeks. All patients had transient improvement in vision, but then experienced decreasing visual acuity over the next four to six months. Intravitreal amphotericin B was given again in all patients with only transient improvement of vision.

In patient 1 the lens implant was removed, but in the other three patients the implant was not removed either because the patient was a poor operative risk (patients 2 and 4 ) or because of secondary problems of retinal detachment and low intraocular pressure (patient 3 ).

During fluconazole therapy the three patients

\begin{tabular}{|c|c|c|c|c|c|c|}
\hline \multirow[t]{2}{*}{ Patient no. } & \multirow[t]{2}{*}{ Age/Sex } & \multicolumn{4}{|c|}{ Treatment prior to fluconazole therapy } & \multirow[t]{2}{*}{ Outcome } \\
\hline & & Surgery & $\begin{array}{l}\text { Steroid } \\
\text { therapy }\end{array}$ & $\begin{array}{l}\text { Intravitreal } \\
\text { antifungals }\end{array}$ & $\begin{array}{l}\text { Implant } \\
\text { removed }\end{array}$ & \\
\hline 1 & $66 / \mathrm{M}$ & $\begin{array}{l}\text { Posterior } \\
\text { capsulotomy, } \\
\text { vitrectomy } \times 2\end{array}$ & $\begin{array}{l}\text { Topical, } \\
\text { paraocular, } \\
\text { oral }\end{array}$ & Amphotericin $\times 2$ & Yes & $\begin{array}{l}\text { Lens removed, }(+) \\
\text { C. parapsilosis. } 2 \text { years } \\
\text { post-Flu, V.A. } 20 / 25 \text { and } \\
\text { no inflammation }\end{array}$ \\
\hline 2 & $70 / \mathrm{F}$ & $\begin{array}{l}\text { Posterior } \\
\text { capsulotomy, } \\
\text { vitrectomy } \times 2\end{array}$ & $\begin{array}{l}\text { Topical, } \\
\text { intravitreal }\end{array}$ & Amphotericin $\times 2$ & No & $\begin{array}{l}\text { V.A. improved from count } \\
\text { fingers to } 20 / 40.5 \text { months } \\
\text { post-Flu, vitreous (+) } \\
\text { C. parapsilosis }\end{array}$ \\
\hline 3 & $74 / \mathrm{F}$ & $\begin{array}{l}\text { Posterior } \\
\text { capsulotomy, } \\
\text { vitrectomy } \times 3 \text {, } \\
\text { scleral buckle }\end{array}$ & $\begin{array}{l}\text { Topical, } \\
\text { paraocular } \\
\times 2, \text { oral }\end{array}$ & $\begin{array}{l}\text { Amphotericin } \times 3 \\
\text { Miconazole } \times 1\end{array}$ & No & $\begin{array}{l}\text { V.A. } 20 / 70 \text { post-Flu } 5 \\
\text { months post-Flu, } \\
\text { increasing inflammation, } \\
\text { Flu begun again } 7 \text { months } \\
\text { later }\end{array}$ \\
\hline 4 & $70 / \mathrm{F}$ & $\begin{array}{l}\text { Posterior } \\
\text { capsulotomy, } \\
\text { vitrectomy } \times 2\end{array}$ & $\begin{array}{l}\text { Intravitreal, } \\
\text { topical }\end{array}$ & Amphotericin $\times 2$ & No & $\begin{array}{l}\text { V.A. improved from count } \\
\text { fingers to } 20 / 40.4 \text { months } \\
\text { post-Flu, vitreous (t) } \\
\text { C. parapsilosis }\end{array}$ \\
\hline
\end{tabular}


with ocular pain had relief and all patients had improvement in visual acuity and a decrease in inflammation noted on examination. The patient who had the lens implant removed had return of his visual acuity to $20 / 25$, has done well for over two years since fluconazole was stopped, and presumably is cured. The three patients in whom the lens implant was not removed did well while on fluconazole, but all relapsed with decreasing visual acuity four to five months after therapy was stopped. Two patients had vitreous aspiration performed four and five months after therapy was stopped, and both showed growth of C. parapsilosis on culture.

\section{Discussion}

Post-surgical Candida endophthalmitis is a subacute to chronic infection appearing weeks to months after surgery $[2,3,11]$. It mimics infection with other pathogens of low virulence, such as Propionobacterium acnes, which is found more frequently as a cause of post-operative endophthalmitis in patients with intraocular lens implants [3]. Post-surgical fungal endophthalmitis typically results in indolent, smouldering intraocular inflammation with mild pain and external signs similar to the findings with $P$. acnes infection. Pain, decreased visual acuity, and intraocular inflammation are also seen in postoperative, non-infectious uveitis, which is a more common complication than infection during the post-operative period.

The similarity in findings between postoperative sterile uveitis and infection with pathogens of low virulence probably explains why all of our patients and most reported cases of postoperative Candida endophthalmitis were initially treated with corticosteroids. Although valuable in decreasing inflammation, it is likely that the use of corticosteroids increased the progression of Candida infection in these patients.

It is essential that in all cases of post-operative endophthalmitis cultures be performed to ascertain if micro-organisms are present. The highest yields are from vitreal aspirates or vitrectomy [2]. Organisms are often present in low numbers and need to be assiduously sought by appropriate culture techniques, including use of aerobic and anaerobic growth conditions and use of several different media to allow growth of both bacteria and fungi.

C. parapsilosis has been implicated in previous reports as a cause of post-operative endophthalmitis following cataract extraction alone $[11,12]$ and with intraocular lens implantation $[1,2,6]$.
Most notable was an outbreak of $C$. parapsilosis endophthalmitis traced to contaminated balanced salt solution used intra-operatively [1, 2]. Thirteen cases were documented to be culture positive for $C$. parapsilosis, and the implicated lot of irrigating solution also yielded $C$. parapsilosis [1]. All of these patients had an indolent postoperative endophthalmitis with symptoms and signs similar to those noted in our patients.

Although a less common cause of fungaemia than C. albicans, C. parapsilosis is frequently implicated as a cause of infection in patients receiving total parenteral nutrition and in those with prosthetic devices, and is often a nosocomially acquired infection [13-16]. C. parapsilosis appears to be less pathogenic than C. albicans or C. tropicalis on the basis of experimental animal studies [13], and patients with $C$. parapsilosis fungaemia appear to have a lower mortality than those with fungaemia due to $C$. albicans and C. tropicalis $[13,14,16]$.

Treatment of fungal endophthalmitis is difficult. Amphotericin B has been used successfully to treat haematogenously acquired Candida endophthalmitis $[17,18]$. In a rabbit model of haematogenous Candida endophthalmitis, intravenous amphotericin B was superior to intravenous fluconazole in eradicating the fungus from both the choroid-retina and the vitreous body [19]. Intraocular administration of amphotericin $B$ has also been used successfully in some cases of Candida endophthalmitis $[2,6,11,20]$.

Post-surgical exogenously acquired Candida endophthalmitis appears to be more difficult to treat than haematogenously acquired infection [21]. The infection is usually very low grade with minimal inflammation, thus leading to low concentrations of antifungal drugs in the tissues [7, 9]. Also, the presence of a foreign body, in the case of infection following intraocular lens implantation, makes eradication of fungal infection difficult $[3,4]$. One additional point that may be important is that although Candida infection may be sight-threatening, many patients and physicians are unwilling to use long-term systemic amphotericin $\mathrm{B}$ to treat this localized infection $[2,7,20]$. This is especially true in elderly individuals, who receive most intraocular lens implants, and who are more likely to have preexisting renal insufficiency and tolerate amphotericin B less well [22].

The best reported results for treating Candida endophthalmitis associated with an infected lens implant are those which utilized vitrectomy combined with intravitreal injection of amphotericin B and systemic amphotericin B and flucytosine $[2,6]$. In 13 patients, Stern et al. reported that visual acuities of $20 / 60$ or better were obtained 
in five patients treated this way; however, two patients had negative cultures to begin with and one required subsequent removal of the lens [2]. Thus, only two of 11 patients who had cultures positive for C. parapsilosis had a good result with this method of treatment. Three patients required removal of the lens, only one of whom had a good outcome. Stransky's patient had a good response to pars plana vitrectomy, intravitreal amphotericin B, and systemic flucytosine, but she did not have a lens implant in place [11].

All of our patients failed treatment with vitrectomy and intravitreal amphotericin B. Although the initial response to intravitreal amphotericin $\mathrm{B}$ was favourable, decreasing visual acuity and relapse with positive cultures ultimately followed. The course was indolent, so that relapse was not obvious for several months. In every case, either the patient was unwilling or unable to take systemic amphotericin B, or the physician caring for the patient was unwilling to embark on this course of therapy. The one patient who did have amphotericin $B$ refused to take more than seven days of therapy.

Fluconazole is very attractive as therapy for Candida endophthalmitis. It has been used to treat a variety of different types of Candida infections, can be used safely for prolonged periods of time, and has been shown to achieve good concentrations in many body fluids, including the eye $[9,10,18]$. In rabbits, Walsh et al. showed that fluconazole concentrations in the vitreous and the choroid were approximately $50 \%$ of those found in plasma at peak plasma concentrations and almost twice as high as plasma concentrations $24 \mathrm{~h}$ after an intravenous dose of fluconazole [10]. These results confirmed those of Savani $e t$ al. [9], who showed in rabbits that fluconazole penetrated the aqueous humour and vitreous body even in the absence of inflammation, an important point in patients such as ours with low-grade inflammation.

However, data obtained in rabbits with experimental Candida endophthalmitis raise questions about the efficacy of fluconazole in treating Candida endophthalmitis $[9,19]$. Fluconazole proved to be less effective than either amphotericin $\mathrm{B}$ or other azoles, even though higher drug levels were measured for fluconazole than for the other drugs $[9,19]$. It should be noted that the rabbit model of haematogenously acquired Candida endophthalmitis does not replicate Candida infection of an intraocular lens implant, nor does short-term therapy of seven to 24 days used in these studies necessarily predict what will occur in patients treated for much longer.

Prior experience with fluconazole for Candida endophthalmitis in humans has been reported in eight patients [23-26]. In seven patients with haematogenous endophthalmitis, clinical success was noted with fluconazole given in doses of $100 \mathrm{mg}$ to $400 \mathrm{mg}$ daily for $3-5$ weeks [24-26]. Only one of these patients had cultures performed [26]; follow-up in four patients for 4-7 months confirmed probable cure in all four [25, 26]. Another patient was treated with $100 \mathrm{mg}$ fluconazole daily for 15 weeks for $C$. parapsilosis endophthalmitis following corneal transplant. This patient's infection recurred 12 weeks after therapy was stopped [23].

Although all of our patients improved clinically, only one, the patient who had the lens implant removed, was cured. If at all possible, both removal of the foreign body and antifungal therapy should be carried out to enhance the possibility for a cure. If it is difficult to remove the implant, as occurred with several of our elderly patients, then chronic suppression with a relatively non-toxic oral drug, such as fluconazole, is a reasonable option. In this case, therapy probably should be continued for life to suppress recurrence of the infection.

\section{Acknowledgement}

Pfizer-Roerig, Inc. generously supplied fluconazole for use by these patients.

\section{References}

I McCray, E., Rampell, N., Solomon, J. L., Bond, W. W., Martone, W. J. \& O'Day, D. (1986) Outbreak of Candida parapsilosis endophthalmitis after cataract extraction and intraocular lens implantation. 7. Clin. Microbiol. 24, 625-628.

2 Stern, W. H., Tamura, E., Jacobs, R. A. et al. (1985) Epidemic post-surgical Candida parapsilosis endophthalmitis. Ophthalmology 92, 1701-1709.

3 Rao, N. A., Nerenberg, A. V. \& Foster, D. J. (1991) Torulopsis candida (Candida famata) endophthalmitis simulating Propionobacterium acnes syndrome. Arch. Ophthalmol. 109, 1718-1721.

4 Pettit, T. H., Olson, R. J., Foos, R. Y. \& Martin, W. J. (1980) Fungal endophthalmitis following intraocular lens implantation. A surgical epidemic. Arch. Ophthalmol. 98, 1025-1039.

5 Rummelt, V., Ruprecht, K. W., Boltze, H. J. \& Naumann, G. O. H. (1991) Chronic Alternaria alternata endophthalmitis following intra-ocular lens implantation. Arch. Ophthalmol. 109, 178.

6 Gilbert, C. M. \& Novak, M. A. (1984) Successful treatment of postoperative Candida endophthalmitis in an eye with an intraocular lens implant. $A m$. 7. Ophthalmol. 97, 593-595.

7 Green, W. R., Bennett, J. E. \& Goos, R. D. (1965) Ocular penetration of amphotericin B. Arch. Ophthalmol. 73, 769-775. 
8 Fisher, J. F., Taylor, A. T., Clark, J., Rao, R. \& EspinolIngroff, A. (1983) Penetration of amphotericin B into the human eye. 7. Infect. Dis. 147, 164.

9 Savani, D. V., Perfect, J. R., Cobo, L. M. \& Durack, D. T. (1987) Penetration of new azole compounds into the eye and efficacy in experimental Candida endophthalmitis. Antimicrob. Agents Chemother. 31, 6-10.

10 Walsh, T. J., Foulds, G. \& Pizzo, P. A. (1989) Pharmacokinetics and tissue penetration of fluconazole in rabbits. Antimicrob. Agents Chemother. 33, 467-469.

11 Stransky, T. J. (1981) Postoperative endophthalmitis secondary to Candida parapsilosis. A case treated by vitrectomy and intravitreous therapy. Retina 1, 179-185.

12 Rosen, R. \& Friedman, A. H. (1973) Successfully treated postoperative Candida parakrusei endophthalmitis. Am. 7. Ophthalmol. 76, 574-577.

13 Weems, J. J.Jr. (1982) Candida parapsilosis: Epidemiology, pathogenicity, clinical manifestations, and antimicrobial susceptibility. Clin. Infect. Dis. 14, 756-766.

14 Meunier-Carpentier, F., Kiehn, T. E. \& Armstrong, D. (1981) Fungemia in the immunocompromised host. Changing patterns, antigenemia, high mortality. Am. 7. Med. 71, 363-370.

15 Plouffe, J. F., Brown, D. G., Silva, J., Eck, T., Stricof, R. L. \& Fekety, F. R. (1977) Nosocomial outbreak of Candida parapsilosis fungemia related to intravenous infusions. Arch. Intern. Med. 137, I686-1689.

16 Komshien, S. V., Uwaydah, A. K., Sobel J. D. \& Crane, L. R. (1989) Fungemia caused by Candida species and Torulopsis glabrata in the hospitalized patient: Frequency, characteristics, and evaluation of factors infuencing outcome. Rev. Infect. Dis. 11, 379-390.

17 Edwards, J. E. \& Filler, S. G. (1992) Current strategies for treating invasive candidiasis: Emphasis on infections in non-neutropenic patients. Clin. Infect. Dis. 14 (Suppl. 1), S106-S113.

18 Schmid, S., Martenet, A. C. \& Oelz, O. (1991) Candida endophthalmitis: Clinical presentation, treatment, and outcome in 23 patients. Infection 19, 21-24.

19 Filler, S. G., Crislip, M. A., Mayer, C. L. \& Edwards, J. E. Jr. (1991) Comparison of fluconazole and amphotericin B for treatment of disseminated candidiasis and endophthalmitis in rabbits. Antimicrob. Agents Chemolher. 35, 288-292.

20 Perraut, L. E. Jr.,,Perraut, L. E., Bleiman, B. \& Lyons, J. (1981) Successful treatment of Candida albicans endophthalmitis with intravitreal amphotericin B. Arch. Ophthalmol. 99, 1565-1567.

21 Jones, D. B. (1978) Therapy of postsurgical fungal endophthalmitis. Ophthalmology 85, 357-373.

22 Kauffman, C. A. (1992) Fungal infections. Clin. Geriatr. Med. 8, 777-791.

23 Van't Wout, J. W., Mattie, H. \& van Furth, R. (1988) A prospective study of the efficacy of fluconazole (UK 49,858 ) against deep-seated fungal infections. 7. Antimicrob. Chemother. 21, 665-672.

24 Ishibashi, Y. (1991) Oral fluconazole for endogenous fungal endophthalmitis. XI Congress of the International Society for Human and Animal Mycology, Monireal 1991, p. 140.

25 Cruciani, M., Di Perri, G., Concia, E. et al. (1990) Fluconazole and fungal ocular infection. 7. Antimicrob. Chemother. 25, 718-720.

26 Fera, G., Maci, A. M., Schiraldi, O., Auteri, P. \& Santoro, S. (1991) Chororetinitis caused by Candida albicans with systemic candidiasis in a patient with acquired immunodeficiency syndrome: Results of a treatment with fluconazole. Curr. Ther. Res. 49, 1103-1 107. 